\title{
Computed tomographic scan evaluation of pulmonary blastomycosis
}

\author{
Suzanne Ronald BSc MSc${ }^{1}$, Jacek Strzelczyk MD², Sean Moore $\mathrm{MD}^{3}$, Elly Trepman $\mathrm{MD}^{4,5}$, Mary Cheang M Math ${ }^{6}$, \\ Bill Limerick CPHI CRSP ${ }^{7}$, Lyle Wiebe CPHI CRSP ${ }^{7}$, Pete Sarsfield $\mathrm{MD}^{7}$, Kerry MacDonald $\mathrm{MD}^{8}$, \\ Michael Meyers MD², John M Embil MD FRCPC ${ }^{4,9}$
}

S Ronald, J Strzelczyk, S Moore, et al. Computed tomographic scan evaluation of pulmonary blastomycosis. Can J Infect Dis Med Microbiol 2009;20(4):112-116.

BACKGROUND: Blastomycosis is an uncommon granulomatous pulmonary and extrapulmonary infectious disease caused by the thermally dimorphic fungus Blastomyces dermatitidis. Diagnosis may be delayed or difficult because of varied presentation. The characteristics of blastomycosis on computed tomographic (CT) scan of the chest are not well characterized.

METHODS: The images from 34 chest CT scans from patients with confirmed pulmonary blastomycosis were retrospectively reviewed.

RESULTS: The most common CT findings were air bronchograms in 22 patients $(65 \%)$, consolidation in 21 patients (62\%), nodules (smaller than $3 \mathrm{~cm}$ ) in 21 patients $(62 \%)$ and lymph node enlargement (mediastinal and hilar nodes combined) in 12 patients $(35 \%)$. Only four patients (12\%) had a miliary pattern.

CONCLUSIONS: A specific abnormality characteristic of pulmonary blastomycosis was not identified on CT scanning. The diagnosis can only be made in the context of a high index of clinical suspicion with histological or culture confirmation.

\section{L'évaluation tomodensitométrique d'une blastomycose pulmonaire}

\begin{abstract}
HISTORIQUE : La blastomycose est une maladie granulomateuse infectieuse pulmonaire et extra-pulmonaire rare causée par le champignon dimorphe thermique Blastomyces dermatiditis. Le diagnostic peut être retardé ou difficile à poser en raison de sa présentation diversifiée. Les caractéristiques de la blastomycose à la tomodensitométrie thoracique ne sont pas bien établies.

MÉTHODOLOGIE : On a procédé à une analyse prospective des images de 34 tomodensitométries thoraciques de patients atteints d'une blastomycose pulmonaire confirmée.

RÉSULTATS : Les principales observations tomodensitométriques étaient des bronchogrammes aériens chez 22 patients (65\%), une consolidation chez 21 patients $(62 \%)$, des nodules (de moins de $3 \mathrm{~cm}$ ) chez 21 patients (62\%) et une hypertrophie des ganglions lymphatiques (médiastinaux et hilaires combinés) chez 12 patients (35\%). Seulement quatre patients $(12 \%)$ présentaient un motif miliaire.

CONCLUSIONS : On n'a pas repéré de caractéristiques d'anomalie spécifique de blastomycose pulmonaire à la tomodensitométrie. On ne peut poser le diagnostic qu'en présence d'un fort indice de suspicion clinique, confirmé par histologie et culture.
\end{abstract}

Key Words: Blastomyces dermatitidis; Fungus; Imaging; Infection; Lung

$\mathrm{B}$ lastomycosis is an uncommon granulomatous infectious disease caused by the thermally dimorphic fungus Blastomyces dermatitidis (1). B dermatitidis exists in mycelial form in the soil of warm, moist, wooded areas that are rich in organic debris (2-7). When mycelia are disturbed, conidia are inhaled and convert to thick-walled budding yeast at body temperature (8). Clusters of neutrophils and noncaseating granulomas with epithelioid cells characterize the pyogranulomatous response that ensues. Hematogenous dissemination may occur, resulting in extrapulmonary disease. Primary cutaneous blastomycosis is uncommon $(9,10)$, and person-toperson transmission is rare $(11,12)$.

$B$ dermatitidis is difficult to isolate from nature and there is no sensitive or specific skin or serological test to confirm infection (13). The endemic area for B dermatitidis in North America includes the Ohio and Mississippi River basins and the Canadian and American regions bordering the Great Lakes $(14,15)$. Studies performed during outbreaks indicate that infection occurs in a high percentage of people exposed but symptomatic disease occurs in fewer than one-half, with the median incubation period ranging from 30 to 45 days (16).
In symptomatic patients, the clinical presentation is diverse, including a variety of pulmonary and extrapulmonary manifestations (17-19). Pulmonary disease may be acute or chronic and can mimic pyogenic bacterial or fungal infection, tuberculosis and malignancies. Dissemination most commonly involves skin, bone and the genitourinary system $(17,19,20)$. It is unclear what factors lead to the different manifestations of blastomycosis, such as localized or disseminated disease. It also is not known why some individuals develop self-limited pulmonary disease and others develop a more diffuse pulmonary process or widespread disease.

The radiographic and clinical manifestations of pulmonary blastomycosis are varied and nonspecific, making the diagnosis difficult (18,21-28). Localized (lobar or segmental) consolidation is the most frequently reported radiographic finding $(24,26)$. Miliary pulmonary blastomycosis is an uncommon radiographic presentation and is frequently mistaken for tuberculosis $(19,23)$; this presentation may occur in both immunocompetent and immunocompromised individuals (29), and may result from hematogenous dissemination $(23)$.

${ }^{1}$ School of Medicine; ${ }^{2}$ Department of Radiology, University of Manitoba, Winnipeg, Manitoba; ${ }^{3}$ Department of Emergency Medicine, Lake of the Woods District Hospital, Kenora, Ontario; ${ }^{4}$ Department of Medical Microbiology, University of Manitoba, Winnipeg, Manitoba; ${ }^{5}$ epartment of Orthopaedic Surgery, Grand Itasca Clinic $\mathcal{E}$ Hospital, Grand Rapids, Minnesota, USA; ${ }^{6}$ Department of Community Health Sciences, Statistical Consulting Unit, University of Manitoba, Winnipeg, Manitoba; ${ }^{7}$ Northwestern Health Unit; ${ }^{8}$ Department of Pathology, Lake of the Woods District Hospital, Kenora, Ontario; ${ }^{9}$ Section of Infectious Diseases, Department of Medicine, University of Manitoba, Winnipeg, Manitoba Correspondence: Dr John M Embil, Infection Control Unit, Health Sciences Centre, MS 673 - 820 Sherbrook Street, Winnipeg, Manitoba R3A 1R9. Telephone 204-787-4654, fax 204-787-2989, e-mail jembil@hsc.mb.ca 
Although the radiographic findings in pulmonary blastomycosis may not distinguish this infection from other conditions $(18,23-28)$, radiography is often among the initial studies done. Chest radiographs in patients with blastomycosis may show nonspecific findings such as air-space disease, nodules, masses, interstitial disease, pleural effusions and cavitation (18,30-32). A previous review of chest computed tomography (CT) scans in 16 patients with blastomycosis showed mass lesions, consolidation, air bronchograms, intermediate-sized nodules, satellite lesions, pleural thickening, small effusions and cavitation, but there was no correlation evident between the CT abnormalities and the clinical presentation (33). We hypothesized that a larger evaluation of CT scans in people with confirmed pulmonary blastomycosis may improve the understanding of the radiographic findings and diagnosis. Therefore, a retrospective review of chest CT scans in patients with blastomycosis was performed.

\section{METHODS}

\section{Subjects}

A retrospective review of medical records and CT scan images was performed for patients with confirmed blastomycosis diagnosed at hospitals with more than 150 beds in the Canadian province of Manitoba and at the Lake of the Woods District Hospital, Kenora, Ontario, during a 17.7-year period (from January 5, 1987, to August 31, 2004). Patients were identified by a medical records search using a standard diagnosis code for blastomycosis (International Classification of Diseases [ninth revision] code 116.0) (34). A confirmed case of blastomycosis was defined as a clinically compatible illness with documented isolation of $B$ dermatitidis from sputum, bronchial washings or tissue specimens $(14,35)$. Approval for this project was granted by the Health Research Ethics Board at the Bannatyne Campus, University of Manitoba, Winnipeg, Manitoba.

There were 353 patients identified with confirmed blastomycosis, of which $35(10 \%)$ could not be evaluated because of incomplete or unavailable records. Medical records of the other 318 patients were evaluated for clinical features, summarized in another report (36). Of these patients, 34 (11\%) (23 men and 11 women) had undergone further imaging evaluation of the chest with CT scanning within six months before or after the diagnosis was established (before diagnosis, 22 patients; same day as diagnosis, six patients; after diagnosis, six patients); these 34 patients comprised the current study group. Twenty-six other patients were excluded because the CT scan was performed more than six months before or after the clinical diagnosis of blastomycosis.

The specific indications for CT scanning were frequently unclear, but generally included pulmonary symptoms in the presence or absence of nondiagnostic chest radiographic findings (before diagnosis) or limited clinical improvement despite initial therapy for blastomycosis (after diagnosis). The CT scans had been performed with varied imaging protocols, including varied technique, contrast agents (infused in 24 patients [71\%] and uninfused in 10 patients [29\%]) and slice thicknesses.

The CT images were evaluated retrospectively by an experienced pulmonary radiologist (MM) and a medical student (SR) for presence and location of lung parenchymal findings (consolidation, air bronchograms, ground glass opacities, atelectasis, hyperexpansion, masses, nodules, miliary pattern,
TABLE 1

Chest abnormalities observed on computed tomographic (CT) scans of patients with blastomycosis*

\begin{tabular}{lccc}
\hline Chest abnormality $^{\dagger}$ & Men, n (\%) & Woman, n (\%) & Total, n (\%) \\
\hline Air bronchogram & $16(70)$ & $6(55)$ & $22(65)$ \\
Consolidation & $15(65)$ & $6(55)$ & $21(62)$ \\
Nodules (<3 cm) & $14(61)$ & $7(64)$ & $21(62)$ \\
Mediastinal lymph nodes $^{\ddagger}$ & $5(22)$ & $6(55)$ & $11(32)$ \\
Cavities & $8(35)$ & $2(18)$ & $10(29)$ \\
Satellite nodules & $7(30)$ & $3(27)$ & $10(29)$ \\
Extension of consolidation $^{\text {to hilum }}{ }^{\S}$ & $9(39)$ & $0(0)$ & $9(26)$ \\
Pleural fluid $_{\text {Mass (>3 cm) }}$ & $8(35)$ & $1(9)$ & $9(26)$ \\
Hilar lymph nodes & & & $8(24)$ \\
Pulmonary scarring & $6(26)$ & $2(18)$ & $6(18)$ \\
Bronchiectasis & $3(13)$ & $3(27)$ & $5(15)$ \\
Miliary & $5(22)$ & $0(0)$ & $4(12)$ \\
Atelectasis & $4(17)$ & $0(0)$ & $4(12)$ \\
\hline
\end{tabular}

${ }^{*} n=34$ patients (23 men and 11 women); 1 CT scan per patient. There were no other significant differences in abnormalities between men and women; ${ }^{\dagger} \mathrm{CT}$ scanning showed hyperexpansion and pulmonary calcification each in 1 man, and pleural thickening in 1 woman; neither ground glass nor lymph node calcification were noted in any CT scan; ${ }^{\ddagger} 12$ patients (35\%) had lymph nodes: 6 patients had only mediastinal lymph nodes, 5 patients had both mediastinal and hilar lymph nodes, and 1 patient had only hilar lymph nodes; ${ }^{\S}$ Extension to hilum was significantly more frequent in men than women $(P<0.02)$. There were no other significant differences in abnormalities between men and women

extension of consolidation to hilum, satellite nodules, pulmonary calcification, bronchiectasis, cavities and pulmonary scarring), pleural pathology (pleural fluid and thickening) and lymph node abnormalities (enlargement and calcification). Typewritten reports of chest radiographs that documented the interpretation of the radiographs by radiologists were reviewed for presence or absence of findings noted on the CT images; these reports were used because the chest radiographic images were not consistently available.

\section{Data analysis}

The data were stored on a computerized database and analyzed using statistical software (SAS for Windows, Version 9.1; SAS Institute, USA). Sex comparisons were done with the $\chi^{2}$ test. McNemar's test for correlated proportions was used to evaluate concordance between chest radiographic versus CT findings, between right versus left lung, and between upper and middle versus lower lobes; concordance was defined as excellent (kappa 0.7 or greater), good to fair (kappa 0.4 to 0.69 ), or poor (kappa less than 0.4). Statistical significance was set at $\mathrm{P}<0.05$.

\section{RESULTS}

The most common CT findings in patients with blastomycosis were air bronchograms, consolidation and nodules, all present in the majority of patients (Table 1 and Figures 1 and 2). Pulmonary nodules (smaller than $3 \mathrm{~cm}$ ) (Figure 2) were more frequently observed than larger masses (larger than $3 \mathrm{~cm}$ ) (Table 1). All $21 \mathrm{CT}$ scans with consolidation had associated air bronchograms, and two CT scans with a mass had associated air bronchograms (one of which also had consolidation). Miliary pattern was infrequent (Table 1 and Figure 3). The 


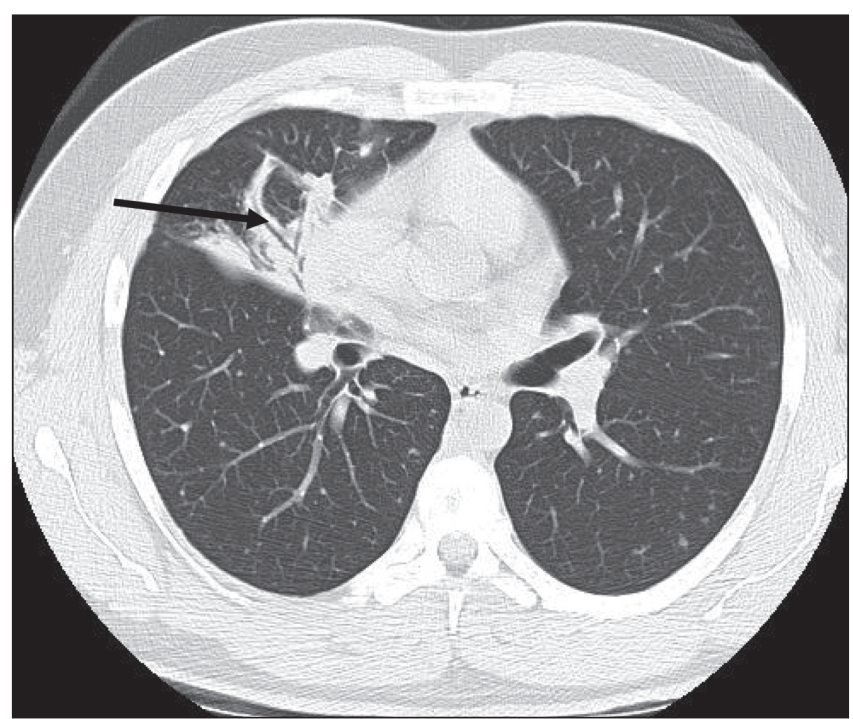

Figure 1) Air bronchogram and consolidation. A 52-year-old man presented with a cutaneous lesion and no other symptoms. Examination of the chest revealed crackles in the right lung region. A chest radiograph showed lobar consolidation, confirmed with a computed tomography scan. The computed tomography scan also shows an air bronchogram (arrow). The diagnosis of blastomycosis was established by skin biopsy. The pulmonary lesion resolved with antifungal therapy

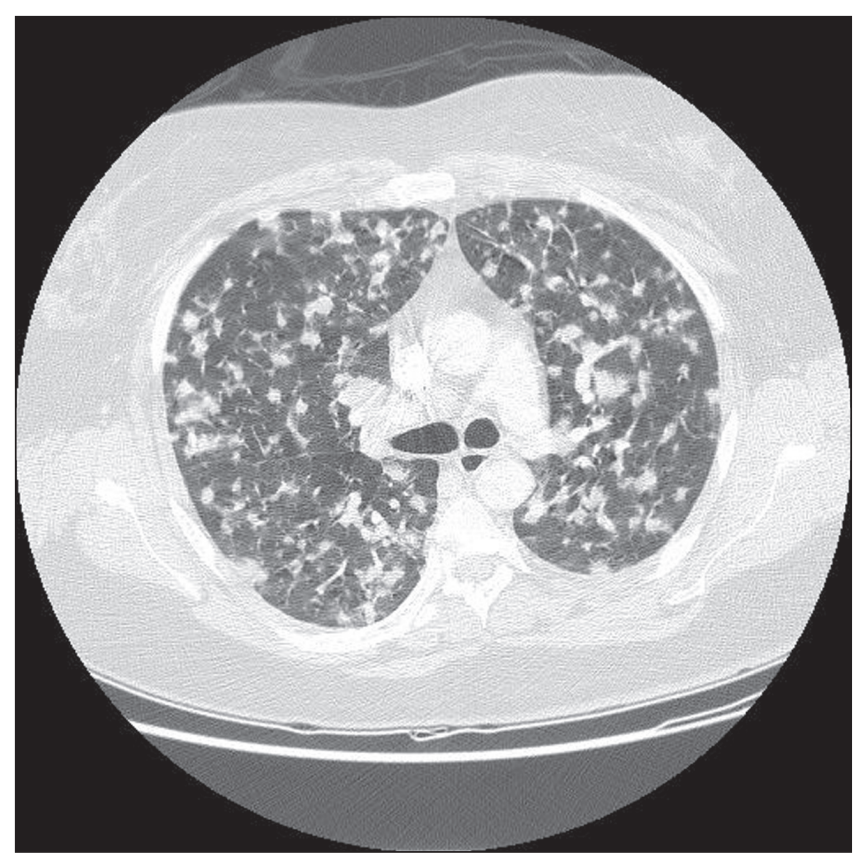

Figure 2) Multiple nodules. A 41-year-old woman presented with dyspnea and no other symptoms. Chest radiograph revealed multiple pulmonary nodules, confirmed with a computed tomography scan. The diagnosis of blastomycosis was confirmed by recovery of Blastomyces dermatitidis on sputum smear and culture

frequency of parenchymal findings was similar between the right and left lungs and between upper and middle compared with lower lobes (Tables 2 and 3). The CT findings did not correlate with the clinical stage of infection.

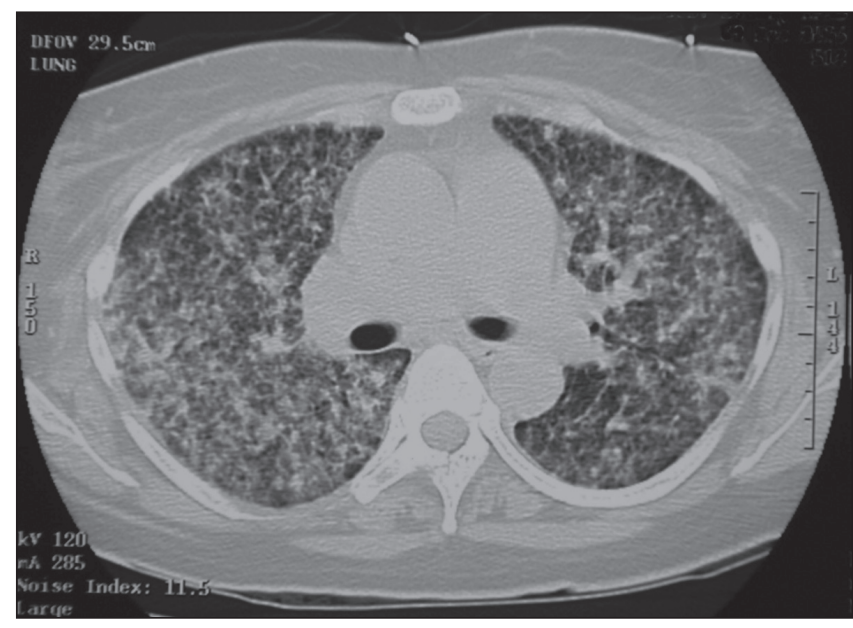

Figure 3) Miliary blastomycosis. A 36-year-old woman presented with rapidly progressive dyspnea. Chest radiographs and computed tomography scan showed miliary pattern present at the time of presentation. The diagnosis of blastomycosis was confirmed by recovery of Blastomyces dermatitidis on sputum smear and culture

\section{TABLE 2}

Pulmonary lobar distribution of parenchymal abnormalities (all lobes) on computed tomographic (CT) scans of patients with blastomycosis*

\begin{tabular}{|c|c|c|c|c|c|c|}
\hline \multirow[b]{2}{*}{$\begin{array}{l}\text { Pulmonary } \\
\text { abnormality }^{\dagger}\end{array}$} & \multicolumn{5}{|c|}{ Number of lobes (\% patients) } & \multirow{2}{*}{$\begin{array}{c}\text { Total } \\
\text { lobes } \\
\text { (all lobes) }\end{array}$} \\
\hline & $\begin{array}{l}\text { Right } \\
\text { upper }\end{array}$ & $\begin{array}{l}\text { Right } \\
\text { middle }\end{array}$ & $\begin{array}{l}\text { Right } \\
\text { lower }\end{array}$ & $\begin{array}{l}\text { Left } \\
\text { upper }\end{array}$ & $\begin{array}{l}\text { Left } \\
\text { lower }\end{array}$ & \\
\hline Air bronchogram & $8(24)$ & $6(18)$ & $12(35)$ & $8(24)$ & $11(32)$ & 45 \\
\hline Nodules $(<3 \mathrm{~cm})$ & $10(29)$ & $6(18)$ & $9(26)$ & $9(26)$ & $11(32)$ & 45 \\
\hline Consolidation & $7(21)$ & $5(15)$ & $12(35)$ & $8(24)$ & $11(32)$ & 43 \\
\hline Satellite nodules & $4(12)$ & $0(0)$ & $2(6)$ & $2(6)$ & $4(12)$ & 12 \\
\hline Cavities & $5(15)$ & $1(3)$ & $2(6)$ & $1(3)$ & $1(3)$ & 10 \\
\hline Miliary & $3(9)$ & $3(9)$ & $3(9)$ & $3(9)$ & $4(12)$ & 16 \\
\hline Mass $(>3 \mathrm{~cm})$ & $4(12)$ & $2(6)$ & $0(0)$ & $1(3)$ & $1(3)$ & 8 \\
\hline $\begin{array}{l}\text { Pulmonary } \\
\text { scarring }\end{array}$ & $2(6)$ & $0(0)$ & $1(3)$ & $2(6)$ & $2(6)$ & 7 \\
\hline Bronchiectasis & $0(0)$ & $0(0)$ & $2(6)$ & $1(3)$ & $1(3)$ & 4 \\
\hline
\end{tabular}

${ }^{*} n=34$ patients; $1 \mathrm{CT}$ scan per patient; ${ }^{\dagger}$ Hyperexpansion and pulmonary calcification each were noted on CT scan in 1 right lower lobe and no other lobes of any CT scans

Enlarged lymph nodes, including mediastinal lymph nodes, were present in approximately one-third of patients, and pleural fluid in approximately one-quarter of patients (Table 1). Hilar lymph notes were noted on the right side in five patients and on the left side in one patient (bilateral in none). Pleural fluid was noted on the right side exclusively in five patients, left side exclusively in three patients, and bilaterally in one patient; pleural thickening was noted in one patient only (right side) (Table 1).

Comparison between findings from CT images and chest radiographic reports showed that concordance was excellent for consolidation (left lung) and mass (left lung); good to fair for extension of consolidation to hilum (right lung), pleural effusion (left side) and miliary pattern (right lung); and poor for consolidation (right lung), extension of consolidation to hilum (left lung), pleural effusion (right side), mass (right lung) and miliary pattern (left lung). The other CT findings could 
not be compared with chest radiography because they were infrequently noted on the chest radiographic reports.

\section{DISCUSSION}

Although the present study has the largest group of chest CT scans to date in patients with confirmed blastomycosis, the data do not demonstrate that CT scanning further clarifies the radiographic abnormalities to assist in diagnosis or understanding of the pathogenesis of this disease. There was no specific abnormality on CT scans diagnostic of blastomycosis, likely reflecting the nonspecific pulmonary response to infection and inflammation. The CT findings were nonspecific, and the radiological differential diagnosis included other pneumonias and malignancy. The use of CT-guided needle aspiration or biopsy as a diagnostic study was not investigated. Nevertheless, the combination of findings of air bronchograms, consolidation, nodules and lymph node enlargement may be suggestive of pulmonary blastomycosis. Therefore, a high index of clinical suspicion is required, and reliable diagnosis of blastomycosis can be established only with recovery of $B$ dermatitidis from cultures $(37,38)$ or more rapidly by direct visualization of the microorganism in cytological or histological specimens $(38,39)$.

Previous chest radiographic studies had reported prevalence rates of consolidation (26\% to 61\%) (26-28,30,33) consistent with the current findings (Table 1). Air bronchograms commonly have been reported, and masses occasionally, consistent with the current results (Table 1) $(26,30,33)$. Air bronchograms within an area of consolidation are a nonspecific finding and may occur with other pneumonias. Air bronchograms in a pulmonary mass, though unusual, are not unique to pulmonary blastomycosis; differential diagnosis includes bronchioloalveolar cell carcinoma, lymphoma, and pseudolymphoma (33). The common finding of nodules (Table 1 ) also has been previously reported $(26,33)$, but this, too, is not diagnostic of blastomycosis and may resemble nodules in pulmonary metastatic and other granulomatous diseases.

The present results are consistent with previous data suggesting that chest CT scanning may be more sensitive to lymph node enlargement than radiography in blastomycosis (33). Lymph node enlargement was more frequent in the present patients (Table 1) than previously reported in chest radiographic studies, in which patients with blastomycosis had a frequency of lymph node enlargement less than 20\% $(24,26,40,41)$.

Limitations of study are similar to those inherent in a retrospective study with medical records, including missing or potentially unreliable data such as chest radiographic reports. Selection bias may have occurred if CT scans were done only for sicker patients or those with unknown diagnosis. Chest radiographic images were not available, and radiographic data were not standardized or uniform because the radiology reports had been prepared by different radiologists. Although this is largest CT study available to date, the number of blastomycosis patients with a CT scan is just a small subset of the entire population of patients with blastomycosis (36); there was no control group or comparison with CT studies of other conditions, making it difficult to provide recommendations for the indications to obtain a CT scan. The absence of a control group of blastomycosis patients who did not have a
TABLE 3

Total parenchymal findings for right versus left lungs and for upper and middle (combined) versus lower lobes* on computed tomographic (CT) scans of patients with blastomycosis $^{\dagger}$

\begin{tabular}{lcccc}
\hline & \multicolumn{4}{c}{ Patients, n (\%) } \\
\cline { 2 - 5 } $\begin{array}{l}\text { Pulmonary } \\
\text { abnormality }\end{array}$ & $\begin{array}{c}\text { Right lung } \\
\text { (total) }\end{array}$ & $\begin{array}{c}\text { Left lung } \\
\text { (total) }\end{array}$ & $\begin{array}{c}\text { Upper and } \\
\text { middle lobes } \\
\text { (total) }\end{array}$ & $\begin{array}{c}\text { Lower } \\
\text { lobes } \\
\text { (total) }\end{array}$ \\
\hline Air bronchogram & $26(76)$ & $19(56)$ & $22(65)$ & $23(68)$ \\
Nodules (<3 cm) & $25(74)$ & $20(59)$ & $25(74)$ & $20(59)$ \\
Consolidation & $24(71)$ & $19(56)$ & $20(59)$ & $23(68)$ \\
Satellite nodules & $6(18)$ & $6(18)$ & $6(18)$ & $6(18)$ \\
Cavities & $8(24)$ & $2(6)$ & $7(21)$ & $3(9)$ \\
Miliary & $9(26)$ & $7(21)$ & $9(26)$ & $7(21)$ \\
Mass (>3 cm) & $6(18)$ & $2(6)$ & $7(21)$ & $1(3)$ \\
Pulmonary scarring & $3(9)$ & $4(12)$ & $4(12)$ & $3(9)$ \\
Bronchiectasis & $2(6)$ & $2(6)$ & $1(3)$ & $3(9)$ \\
\hline
\end{tabular}

*There were no significant differences between right versus left lung or between upper and middle versus lower lobes; ${ }^{\dagger} n=34$ patients; 1 CT scan per patient

CT scan makes it difficult to determine if CT affected the treatment and outcome.

Although no diagnostic advantage of CT scanning was evident, CT scanning is frequently done during diagnostic evaluation of patients with nonresolving pulmonary pathology including blastomycosis. CT scanning of the thorax may be indicated in patients suspected of having blastomycosis as in other patients with an undiagnosed pulmonary condition to exclude other possible causes of pulmonary disease or as a method to facilitate needle-guided biopsy and culture.

ACKNOWLEDGEMENTS: The authors are grateful for generous support of SR by the Kenneth and Elizabeth Walton Research Studentship, University of Manitoba, Winnipeg, Manitoba.

\section{REFERENCES}

1. Medoff G, Painter A, Kobayashi GS. Mycelial-to-yeast phase transitions of the dimorphic fungi Blastomyces dermatitidis and Paracoccidiodes brasiliensis. J Bacteriol 1987;169:4055-60.

2. Denton JF, McDonough ES, Ajello L, Ausherman RJ. Isolation of Blastomyces dermatitidis from soil. Science 1961;133:1126-7.

3. Denton JF, Di Salvo AF. Isolation of B. dermatitidis from natural sites at Augusta, Georgia. Am J Trop Med Hyg 1964;13:716-22.

4. Denton JF, Di Salvo AF. Additional isolations of Blastomyces dermatitidis from natural sites. Am J Trop Med Hyg 1979;28:697-700.

5. Dixon OM, Shadomy H. In vitro growth and sporulation of Blastomyces dermatitidis on woody plant material. Mycologia 1977;69:1193-4.

6. Bakerspigel A, Kane J, Schaus D. Isolation of Blastomyces dermatitidis from an earthen floor in southwestern Ontario, Canada. J Clin Microbiol 1986;24:890-1.

7. Sarosi GA, Serstock DS. Isolation of Blastomyces dermatitidis from pigeon manure. Am Rev Resp Dis 1976;114:1179-83.

8. Schwarz J, Baum GL. Blastomycosis. Am J Clin Pathol 1951;21:999-1029.

9. Larson DM, Eckman MR, Alber RL, Goldschmidt VG. Primary cutaneous (inoculation) blastomycosis: An occupational hazard to pathologists. Am J Clin Pathol 1983;79:253-5.

10. Gnann JW, Bressler GS, Bodet CA, Avent CK. Human blastomycosis after a dog bite. Ann Intern Med 1983;98:48-9.

11. Watts EA, Gard PD, Tuthill SW. First reported case of intrauterine transmission of blastomycosis. Pediatr Infect Dis 1983;2:308-10. 
12. Craig MW, Davey WN, Green RA. Conjugal blastomycosis. Am Rev Respir Dis 1970;102:86-90.

13. Bradsher RW. Histoplasmosis and blastomycosis. Clin Infect Dis 1996;22 Suppl. 2:S102-111.

14. Centers for Disease Control and Prevention (CDC). Blastomycosis - Wisconsin, 1986-1995. MMWR Morb Mortal Wkly Rep 1996;45:601-3.

15. Medoff G, Kobayashi GS. Systemic fungal infections: An overview. Hosp Pract 1991;26:41-52.

16. Klein BS, Vergeront JM, Weeks RJ, et al. Isolation of Blastomyces dermatitidis in soil associated with a large outbreak of blastomycosis in Wisconsin. N Engl J Med 1986;314:529-34.

17. Oppenheimer M, Embil JM, Black B, Wiebe L, Limerick B, MacDonald K, et al. Blastomycosis of bones and joints. South Med J 2007;100:570-8.

18. Fang W, Washington L, Kumar N. Imaging manifestations of blastomycosis: a pulmonary infection with potential dissemination. Radiographics 2007;27:641-55.

19. Embil JM, Aoki FY, Hershfield ES, Meyers MP. Respiratory failure in a man with bone and lung lesions. Hosp Pract 1998;33:211-9

20. Chapman SW. Blastomyces dermatitidis. In: Mandell GL, Bennett JE, Dolin R, eds. Mandell, Douglas, Bennett's Principles and Practice of Infectious Diseases, 6th edn. Philadelphia: Elsevier; 2005:3026-40.

21. Pfister AK, Godwin AW, Squire EW, Ellison AB, Walker JH. Pulmonary blastomycosis: Roentgenographic clues to the diagnosis. South Med J 1966;59:1441-7.

22. Meyer K, McManus EJ, Maki DC. Overwhelming pulmonary blastomycosis associated with the adult respiratory distress syndrome. N Engl J Med 1993;329:1231-6.

23. Stelling CB, Woodring JH, Rehm SR, Hopper DW, Noble RC. Miliary pulmonary blastomycosis. Radiology 1984;150:7-13.

24. Sheflin JR, Campbell JA, Thompson GP. Pulmonary blastomycosis: Findings on chest radiographs of 63 patients. AJR Am J Roentgenol 1990;154:1177-80.

25. Armstrong JD. Common fungal diseases of the lungs III: Blastomycosis. Radiol Clin North Am 1973;11:169-73.

26. Brown LR, Swensen SJ, Van Scoy RE, Prakash UB, Coles DT, Colby TV. Roentgenologic features of pulmonary blastomycosis. Mayo Clin Proc 1991;66:29-38.

27. Cush R, Light RW, George RB. Clinical and roentgenographic manifestations of acute and chronic blastomycosis. Chest 1976;69:345-9.
28. Rabinowitz JG, Busch J, Buttran WR. Pulmonary manifestations of blastomycosis: radiological support of a new concept. Radiology 1976;120:25-32.

29. Pappas PG, Pottage JC, Powderly WG, et al. Blastomycosis in patients with the acquired immunodeficiency syndrome. Ann Intern Med 1992;116:847-53.

30. Halvorsen RA, Duncan JD, Merten DF, Gallis HA, Putman CE. Pulmonary blastomycosis: Radiologic manifestations. Radiology 1984;150:1-5

31. Fanella S, Vinh DC, Skinner S, Hamza S, Embil JM. Massive pleural effusion in a 10-year-old. Pediatr Infect Dis J 2008;27:851-5.

32. Jay SJ, O'Neill RP, Goodman N, Penman R. Pleural effusion: A rare manifestation of acute pulmonary blastomycosis. Am J Med Sci 1977:274:325-8.

33. Winer-Muram HT Beals DD, Cole FH. Blastomycosis of the lung: CT features. Radiology 1992;182:829-32.

34. International Classification of Diseases. International Classification of Diseases, 9th Revision. Clinical Modification, 4th edition. Los Angeles: Practice Management Information Corporation (PMIC), 1994.

35. Crampton TL, Light RB, Berg GM, et al. Epidemiology and clinical spectrum of blastomycosis diagnosed at Manitoba hospitals. Clin Infect Dis 2002;34:1310-6.

36. Kralt D, Light B, Cheang M, et al. Clinical characteristics and outcomes in patients with pulmonary blastomycosis. Mycopathologia 2009;167:115-24.

37. Chapman SW, Dismukes WE, Proia LA, et al. Clinical practice guidelines for the management of blastomycosis: 2008 update by the Infectious Diseases Society of America. Clin Infect Dis 2008;46:1801-12.

38. Lemos LB, Guo M, Baliga M. Blastomycosis: Organ involvement and etiologic diagnosis. A review of 123 patients from Mississippi. Ann Diagn Pathol 2000;4:391-406.

39. Martynowicz MA, Prakash UBS. Pulmonary blastomycosis: An appraisal of diagnostic techniques. Chest 2002;121:768-73.

40. Busey JF, Baker R, Birch L, et al. Blastomycosis. I. A review of 198 collected cases in Veterans Administration Hospitals: Blastomycosis cooperative study of the Veterans Administration. Am Rev Resp Dis 1964;89:659-72.

41. Fraser RS, Müller NL, Colman N, Paré PD. Fungi and actinomyces. In: Fraser RS, Müller NL, Colman N, Paré PD, eds. Diagnosis of Diseases of the Chest, 4th edn. Philadelphia: WB.Saunders Co, 1999:875-978. 


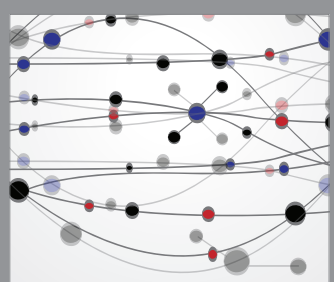

The Scientific World Journal
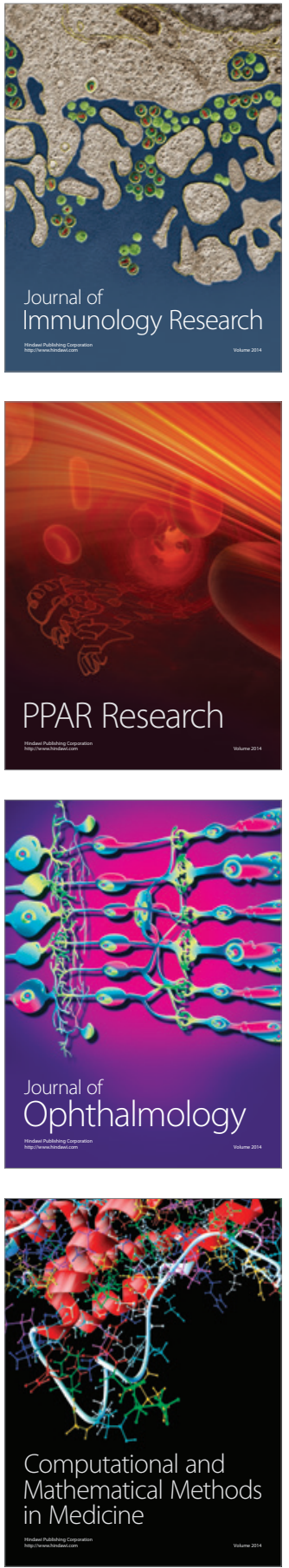

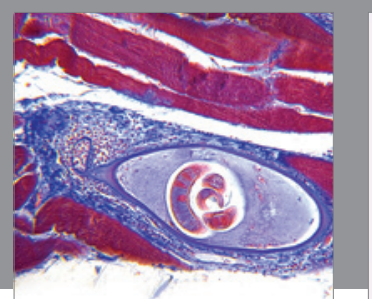

Gastroenterology Research and Practice

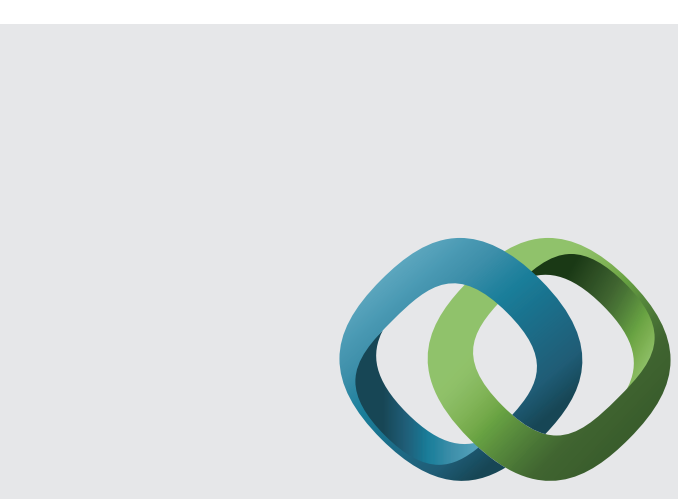

\section{Hindawi}

Submit your manuscripts at

http://www.hindawi.com
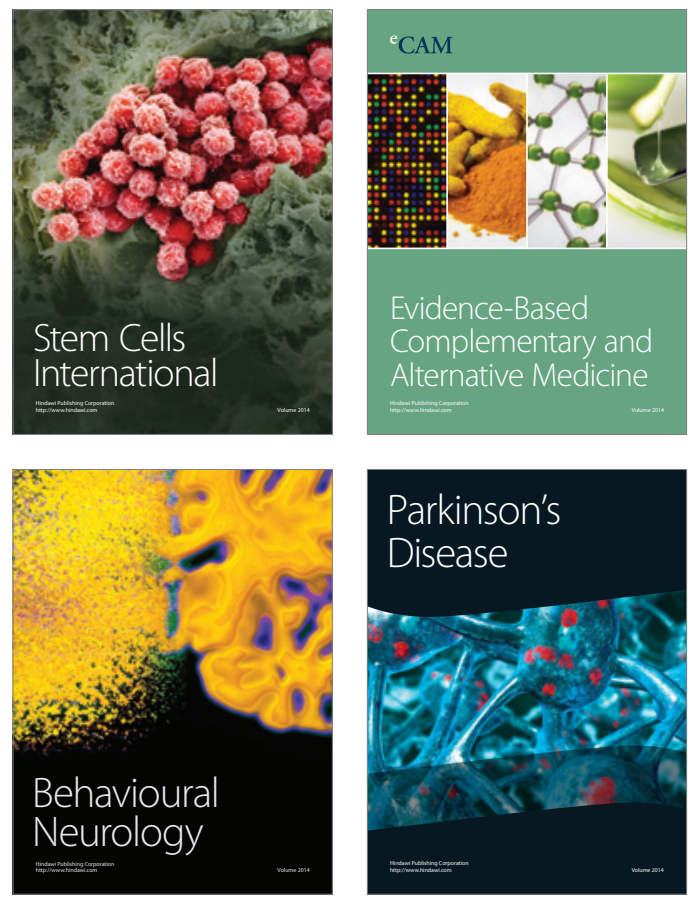
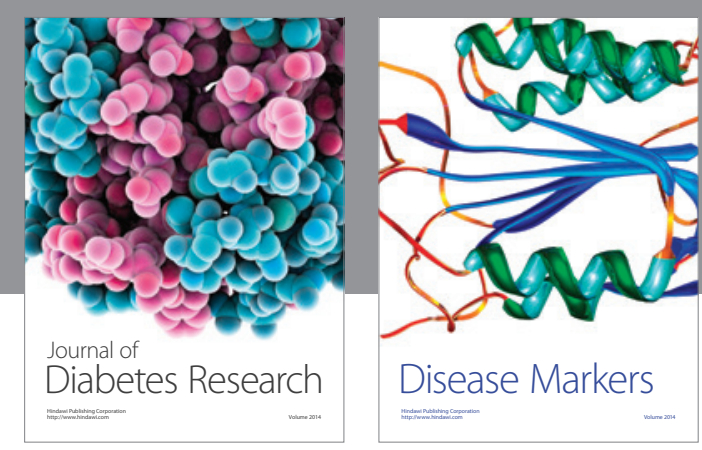

Disease Markers
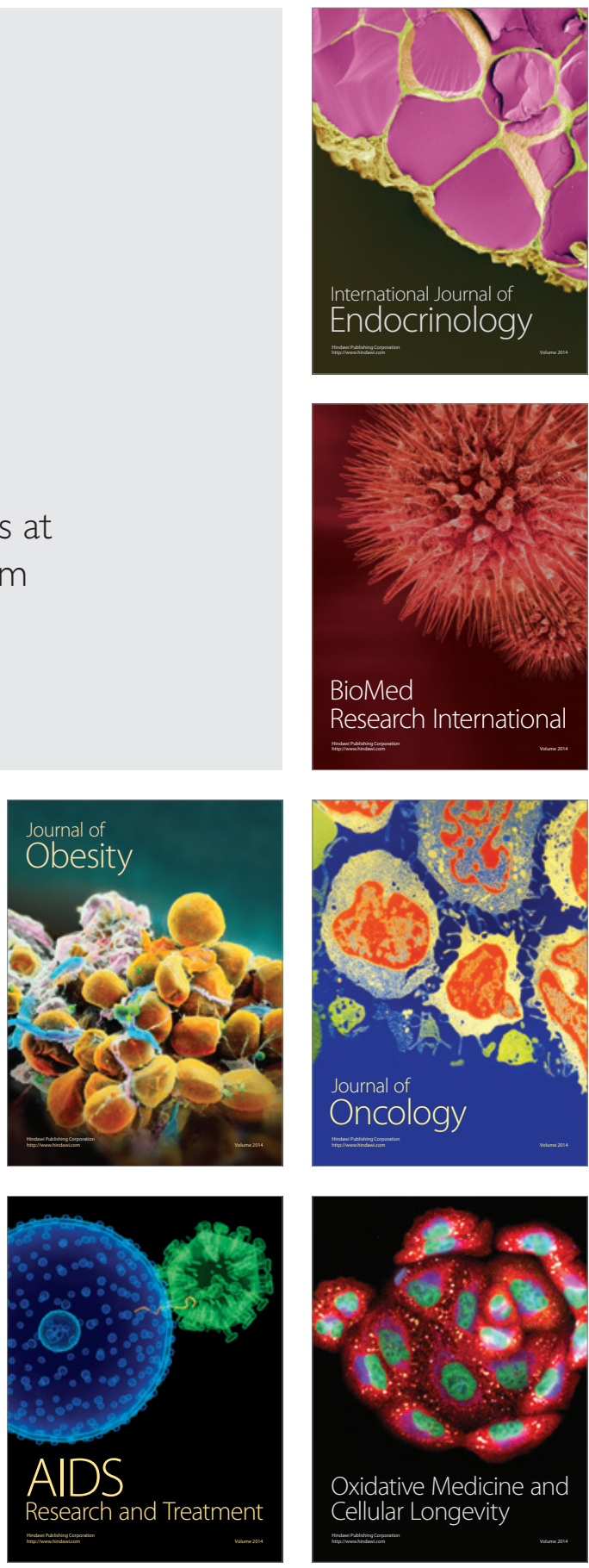